\title{
Migrações Contemporâneas na América Latina e Europa em Perspectiva Comparada - Notas Introdutórias
}

Leonardo Cavalcanti da Silva ${ }^{1}$

Delia Dutra $^{2}$

Gustavo da Frota Simões ${ }^{3}$

Nos últimos anos, vários países latino-americanos têm registrado um incremento sistemático nos fluxos de imigrantes, notadamente daqueles denominados de "novos fluxos migratórios" ${ }^{\natural 4}$. Este fenômeno nos desafia para análises que atentem tanto para uma compreensão quantitativa quanto qualitativa do fenômeno na região, assim como também levanta desafios para as autoridades desses países perante um fenômeno que se apresenta novo pelas suas formas de se manifestar no espaço e no tempo.

O presente dossiê temático intitulado "Migrações na América Latina e na Europa em perspectiva comparada" surgiu a partir da realização do workshop internacional "The International workshop: Migration and Urban Transformations in Latin American and the United Kingdom in the 21st century", organizado pelo Center on Migration, Policy and Society (COMPAS - Oxford University) e o Observatório das Migrações Internacionais (OBMigra Universidade de Brasília), realizado na cidade de Brasília, em junho de 2018, com participantes de ambos centros de pesquisa e pesquisadores convidados. Os integrantes do workshop analisaram diferentes aspectos do fenômeno migratório contemporâneo nas áreas urbanas da

\footnotetext{
${ }^{1}$ Professor Adjunto na Universidade de Brasília (UnB) - Instituto de Ciências Sociais - Centro de Pesquisa e PósGraduação sobre as Américas (CEPPAC), bolsista de Produtividade em Pesquisa (CNPq PQ 2). Brasileiro. Coordenador Científico do Observatório das Migrações Internacionais (OBMigra). leo.cavalcanti.s@ gmail.com

${ }^{2}$ Professora Adjunta na UDELAR (Universidad de la República, Uruguai), CENUR Litoral Norte, Pesquisadora Nível 1 SNI, (ANII, Uruguai). Uruguaia. Professora Colaboradora no PPG-ECsA, Departamento de Estudos Latinoamericanos, Instituto de Ciências Sociais da Universidade de Brasília. deliadutra@gmail.com

${ }^{3}$ Professor Adjunto na Universidade Federal de Roraima (UFRR) - Centro de Ciências Humanas - Curso de Relações Internacionais. Brasileiro. Doutor em Ciências Sociais pelo Centro de Pesquisa e Pós-Graduação sobre as Américas (CEPPAC). Coordenador da Cátedra Sérgio Vieira de Mello da Universidade Federal de Roraima. gufsimoes@gmail.com

${ }^{4}$ CAVALCANTI, L; OLIVEIRA, A. T. de."A caminho da conclusão: meia década de novos fluxos imigratórios no Brasil” en CAVALCANTI, L.; OLIVEIRA, A. T. de; ARAÚJO, D. A inserção dos imigrantes no mercado de trabalho brasileiro. Relatório Anual 2016. Observatórios das Migrações Internacionais; Ministério do Trabalho e Emprego. Brasília, DF: OBMigra, 2016, p.142-145.
}

Revista de Estudos e Pesquisas sobre as Américas V.13 N.1 2019 ISSN: 1984-1639 
América Latina e Reino Unido. Portanto, o workshop abordou uma ampla gama de temas, incluindo: habitação, saúde, emprego, idioma, relações com a comunidade, cidadania, educação, bem-estar, entre outros.

Um grupo de pesquisadores participantes do workshop se propuseram a materializar os debates do evento na forma de um dossiê que abordasse alguns dos temas analisados no workshop. Por este motivo, os textos que compõem este dossiê buscam entender as migrações internacionais em perspectiva comparada e sinalizam como essa abordagem é fundamental para a compreensão das migrações e das sociedades contemporâneas.

Nesse contexto, os movimentos migratórios quando analisados através de comparações, introduzem desafios epistemológicos ao campo dos estudos das migrações e permitem debates sobre teorias e métodos de pesquisa que ajudam a compreender e explicar a complexidade do fenômeno. Dessa forma, o presente número conta com contribuições de autores de diferentes instituições de pesquisa tanto nacionais quanto estrangeiras que abordam as migrações na América Latina e Europa em perspectiva comparada. São onze artigos e uma resenha, alguns escritos em inglês, espanhol ou português, fruto dessa parceria que deu origem a esse número temático.

Dois Pesos e Duas Medidas: a projeção da colonialidade nas políticas de migrações e de cidadania da União Europeia intitula-se o primeiro artigo deste dossiê de autoria de Karine de Souza Silva e Ivan Vieira Piseta. Os autores trabalham com a hipótese de que o processo de supranacionalização das migrações e da identidade comum na UE reitera os elementos da colonialidade devido à concepção fortemente racial que contemplam, que separa os excolonizadores dos ex-colonizados por meio de linhas abissais. Nessa linha, eles buscam descontruir a tese de que a integração regional europeia supera os elementos de classificação social presentes no Estado nacional europeu, em especial quanto às migrações não-europeias.

Por outro lado, o segundo nos provoca a pensar que as políticas migratórias dos países da região não deveriam se espelhar em políticas de fechamento de fronteiras e de acolhida seletiva de seres humanos, senão, em ações que propiciem a construção de sociedades inclusivas onde aos locais e aos recém-chegados lhes sejam garantida uma coexistência pacífica, defendem Laura García-Juan e Berta Güell no seu artigo How to manage migrations in Latin America? The Spanish case as a model to follow. As autoras propõem que, se bem não faz sentido tomar e 
reproduzir modelos externos à região, exemplos como o da Espanha, considerado por elas como um caso bem-sucedido, seria um exemplo a ser levado em conta já que fornece elementos concretos que ajudariam na construção de políticas públicas de integração. O caso espanhol, portanto, é proposto com o fim de inspirar países da América Latina que atualmente estão vivendo o desafio de acolher fluxos migratórios diversos em termos quantitativos e respeito e às suas culturas de origem.

Nesse sentido, no artigo "O princípio do melhor interesse e a nova condição jurídica de crianças refugiadas separadas ou desacompanhadas: uma abordagem sobre Brasil e Itália", Mariana Silva Conte e Paulo Roberto Soares Mendonça argumentam que o caso brasileiro e italiano são dignos de nota no tocante a proteção de um grupo ainda mais vulnerável dentro dos imigrantes: as crianças desacompanhadas ou separadas. Desse modo, os autores explicam a diferença nos conceitos e argumentam que a acolhida às crianças deva passar por um tratamento mais favorável como o concedido na Itália por meio da Lei Zampa. O Brasil embora possua uma resolução conjunta editada em 2017 ainda carece de um instrumento normativo com força de lei sobre a questão das crianças e adolescentes desacompanhados ou separados. Essa diferença é fundamental para o Brasil avançar nessa questão, segundo os autores.

Jeremías Pérez Rabasa e Verónica Jaramillo Fonnegra nos propõem focar a análise no caso da migração dos sengaleses desde uma perspectiva comparada nas cidades de Barcelona e Buenos Aires. No artigo "La criminalización de la migración y el rol de las transnacionales en los países de destino: el caso de los senegaleses en Barcelona y Buenos Aires”, os autores levantam uma análise crítica da criminalização da migração senegalesa buscando, além do mais, compreender o papel das empresas transnacionais na configuração de políticas que impactam os

direitos das pessoas migrantes tanto nos países de origem quanto de destino. Isso porque, segundo eles argumentam, o lobby que exercem tais empresas condicionando o investimento em alguns países, dá como resultado medidas que impactam o mercado de trabalho ao ponto de induzir às pessoas a deixarem seus países de origem, ao mesmo tempo que se torna efetiva a perseguição de trabalhadores migrantes racializados, produzindo agendas criminalizantes da alguns coletivos de migrantes no países de destino.

Em “Migraciones africanas en Argentina y Malta. Una aproximación a su estudio en clave comparada", Gisele Kleidermacher explora de forma comparativa a migração de 
subsaarianos para Argentina e Malta entre os anos 2010 e 2018. Por meio da análise de dados estatísticos, entrevistas semi-estruturadas e observações de migrantes da África Subsaariana, assim como integrantes de ONGs que trabalham com a questão migratória, tanto em Malta quanto na Argentina, a autora observa a existência de 'múltiplas mobilidades'. Com foco na análise da migração senegalesa, aponta para as diversas etapas que conformam esses percursos migratórios: deslocamentos intracontinentales, extracontinentales e fluxos internos, percorrendo rotas comerciais que são facilitadas pelas redes comunitárias.

A situação do Brasil como país de imigração é objeto de análise dos autores Roberto Rodolfo Georg Uebel e Caroline Adorne da Silva no artigo "Politics, Policies and International Immigration in Brazil: recent changes and perspectives". Do país do "sonho brasileiro" para latino-americanos e caribenhos, passou-se para o país das remigrações e emigrações forçadas, argumentam os autores. Eles definem como sendo seu objetivo central fazer uma revisão das cartografias, políticas, rotas e o próprio estado da arte das imigrações internacionais no Brasil para os últimos cinco anos. O que restou do então "novo país das imigrações", se perguntam, após as rupturas ocorridas com o impeachment de 2016 e com a aprovação e vigência da nova Lei de Migração a partir de 2017. Resgatam discussões sobre a migração dos refugiados venezuelanos com direção ao Brasil e suas repercussões no projeto de integração latino-americana. Para finalizar, Uebel e da Silva, levantam interessante discussão sobre as perspectivas imigratórias para o Brasil nos próximos anos em diálogo com questões de defesa, geopolítica e geoeconomia, assim como as migrações ambientais.

Lorena Pereda, Pedro Marchioro, Leonardo Cavalcanti e Márcio de Oliveira também dialogam com a questão brasileira no artigo "Haitianos no Paraná (Brasil) em 2018: estratégias em momento de crise. Contextualizando a migração haitiana de forma geral, os autores classificam-na como uma "tradição" ou "elemento estrutural" e buscam com isso entender as narrativas e as falas de imigrantes haitianos que vieram para o Brasil em um momento de crise econômica ou que por aqui permanecem. Procuram, desse modo, estabelecer os processos migratórios como complexos e que dependem de fatores próprios que nem sempre seguem as realidades econômicas dos países. Nesse sentido, os imigrantes haitianos, segundo os autores, No entanto, não apenas os imigrantes escolhem seus destinos por meio de redes 
migratórias e facilitação na chegada, mas também mediante alguns conhecimentos econômicos e sociais dos locais que irão acolhê-los.

Ainda tendo o Brasil como país de destino, Antônio Tadeu de Oliveira em seu artigo "A migração venezuelana no Brasil: crise humanitária, desinformação e os aspectos normativos procura compreender de forma geral como se dá o fluxo migratório para o Brasil. Oliveira argumenta que a desinformação para com os imigrantes é uma das principais causas de xenofobia e preconceito com relação a esse grupo. O autor ainda diz que poucas pesquisas foram realizadas para compreender de forma mais profunda e adequada esse fenômeno migratório e suas especificidades. A esse respeito, Oliveira traça um panorama dos principais motivos da imigração venezuelana, classifica-a como uma migração laboral em decorrência da crise humanitária na Venezuela e traça um perfil desses imigrantes, procurando assim diminuir o desconhecimento a respeito desse migrante. Além disso, o artigo destaca de forma crítica as principais medidas normativas desenvolvidas pelo governo brasileiro no tocante ao acolhimento desses imigrantes.

Angela Facundo, no artigo intitulado "Deslocamento Forçado na Colômbia e Políticas de Refúgio no Brasil: Gestão de Populações em Êxodo" desenvolve uma pesquisa etnográfica sobre a gestão de populações em deslocamento e seus impactos sobre a formulação de políticas públicas para essas pessoas. Com uma base na chamada Antropologia do Estado, o(a) autor(a) argumenta que não fazer determinadas políticas públicas, ou ainda, fazer de maneira precária é uma ação política forte que produz a alienação de pessoas em situação de vulnerabilidade em decorrência do deslocamento. Nesse sentido, o artigo argumenta que a falta de políticas públicas visíveis e robustas faz com que o Estado brasileiro se coloque em uma posição subalterna ao que o(a) autor(a) chama de "especialistas", que no caso do texto são aqueles especializados em gestão de populações em trânsito, especificamente as agências internacionais, sobretudo, o ACNUR. Nesse sentido, o ACNUR como "especialista" da gestão de populações forçadas a se deslocar estabelece mecanismos, ainda que precários, para gerenciar esses fluxos migratórios no Brasil, auxiliados pelas ONGs.

Tânia Tonhati, no seu artigo Educação e Imigração: a importância do ensino da Sociologia para imigrantes, aborda de forma reflexiva, a relação entre imigração educação. A autora mostra como o aumento de imigrantes no país nas duas últimas décadas trouxe como 
consequência o aumento da entrada de crianças e adolescentes imigrantes no sistema educacional básico do país. Para compreender esse fenômeno, a autora reflete sobre a necessidade de utilizar as ferramentas das ciências sociais, especialmente da Sociologia, com seus instrumentos conceituais, pedagógicos e metodológicos para que a comunidade educativa possa entender melhor as particularidades dos processos migratórios, suas motivações e consequências.

Por último, o artigo de Thiago Assunção "Statelessness in Brazil: from invisibility to the invitation for becoming a citizen" procura compreender o fenômeno da apatridia e como essa condição de não pertencimento afeta mais de 10 milhões de pessoas no mundo. Adotando uma perspectiva ampla, Thiago Assunção primeiramente descreve o fenômeno da apatridia, os instrumentos normativos e suas consequências, além de destacar que existem poucas pesquisas na América Latina sobre o assunto. Em seguida, o autor se detém nos instrumentos que tem como objetivo justamente combater essa condição de "limbo existencial". Por último, o autor faz uma análise de como esse fenômeno pouco conhecido no Brasil ganhou destaque nos últimos anos, especialmente com a introdução da nova lei de migração.

Em suma, com este dossiê e a riqueza dos seus artigos, a Revista de Estudos e Pesquisas sobre as Américas, abre um importante espaço para o debate científico e interdisciplinar sobre as Migrações na América Latina e na Europa em perspectiva comparada. Os autores abordam questões de máxima importância das migrações atuais, tanto na América Latina quanto na Europa, identificando elementos que são próprios dos Estados e suas políticas, mas também as respostas dos migrantes e refugiados a tais políticas. Boa Leitura!

Revista de Estudos e Pesquisas sobre as Américas V.13 N.1 2019 ISSN: 1984-1639 